\title{
A Dialogical Reframing
}

(C) The Author(s) 2014

Reprints and permission: sagepub.com/journalsPermissions.nav DOI: $10.1177 / 154 \mid 3446 / 4554508$

jtd.sagepub.com

@SAGE

Laura This special issue represents the culmination of a journey, which began with Formenti: the introduction of transformative learning (TL) into Europe throughout the monumental task of establishing a network dedicated to TL within the European Society for Research on the Education of Adults (ESREA). Both the authors represented in this issue and the editors played important roles in this journey. In this issue, we are offered four lenses to reflect on TL and possibly reframe it. Of course, the articles were written separately, but now they are connected in the same place and our conversation can start a dialogue. These four pieces can serve to further this reflection and dialogue on what we mean by TL, how it differs from what Michael Newman (2012) refers to as "good learning," and how it might be fostered within formal educational practices as well as within the informal contexts of our daily lives. To begin this special issue, John Dirkx and I would like to engage in a transatlantic dialogue.

After all, we are "researchers of difference" (Norris, \& Sawyer, 2012), living on opposite sides of the Atlantic Ocean, with different academic backgrounds and different languages. I am a newcomer in TL, and you are the editor of this journal. Difference is a powerful means for thinking and learning, "food for perception" (Bateson, 1979, p. 32), provided that we are able to transform it; and dialogue is the human way to transform meaning. TL is facing a new challenge, new differences, with a newly formed European Network that will "interrogate" it. So, I propose to you a conversation about this issue, its contents, and the possibilities of transformation that can be opened by dialogue.

\section{The Origins of This Special Issue}

Laura ESREA is a diverse and heterogeneous family (Formenti, West, \& Formenti: Horsdal, 2014), we speak several of the 24 official languages in Europe, we gather scholars from many disciplines and local academies with their own profiles, requirements, and habits. There is not one culture, in Europe, but many local cultures. The result is that locally everybody wants to be the landlord. In Italy, my country, this is called campanilismo (literally, each single village is proud of its own bell tower). 
When you are living in a competitive system, differences can meanand bring to-irreducible polarities, fights for power, and lack of recognition. Hence, I feel that we need to bring in a lot of collaboration, reciprocal listening, and efforts to understand each other, to harmonize opposites, and bring about a real learning experience. The first network conference in ESREAs "Life history and biography network" - and my first in this social space, 22 years ago-was about "structures" and "subjectivities" in adult education research. An epistemological debate and a theoretical challenge embodied in two leading figuresPeter Alheit and Pierre Dominicé, a German and a French personfrom different academic backgrounds. They materialized the contrast between social and individual interpretations of adult lives but also between the South and the North of Europe, between educational practice and academic research. These dilemmas (there are many of them in our field) suggested to me, very deeply, the possibility of a leap: try to see things in a more complex way, as it is also suggested by Bateson's (1979) “double description" and by Varela's (1976) entanglement of recursive couples of concepts. This was TL for me, a process of (that brought to) a creative composition of opposites, where the social generates the individual while it is generated by it.

John Dirkx: With the start of the new term only a few weeks away, I realize that I will be entering my 27 th year as an academic. During much of this career, I have used my time and energies to pursue a deeper exploration and understanding of what we have come to call TL. Throughout my career, I have been aware of and known a number of scholars from different countries who were writing about TL. But, I never really considered the possibilities of what the scholarly discourse around this idea might look like in other countries or even if it was an aspect of the national or regional discourse around adult learning. Yet, I don't know if I ever thought of TL strictly as a North American phenomenon. Focused as I was on the microcosm of small group and individual learning (Boyd and Associates, 1991), I simply didn't think of TL as a product of historical or cultural contexts. Work on the symposium, the network, and this issue has helped me understand in a deeper way how important such a framing of TL is to the field.

\section{Rethinking Our Theory and Practice}

LF: Dialogue is a compelling experience to improve self-reflectiveness. Which are the relevant issues for you as a researcher? What does it mean to bring TL in the European arena? It cannot be a linear thing, like importing some goods, or worse a form of cultural colonialism. Sometimes I ask myself, is it really new? I am quite suspicious about "new theories"; my understanding of knowledge is that we live in an ecology of ideas, with a circular tautological structure (as all living processes). How could TL become a part of my ecology of ideas? As any learner, I am quite 
satisfied of my thoughts until I go into a compelling situation that obliges me to change my perspective. So I ask myself, do I really need it? What could TL do to my praxis, to my life as a researcher?

JD: Do I really need it? What a great question! It opens to so many additional considerations. For me, your question invites additional dialogue around the purpose of education and of learning. It encourages further thought on the nature of meaningful experiences, and how we continue to construct and reconstruct such meaning in the contexts of our daily lives. It harkens us back to Newman's (2012) essay and to ask, does this idea of TL really point to a substantively different kind of learning? Those of us working within this area would undoubtedly answer in the affirmative, but fewer of us might have this as well thought out as your questions might require.

From my own point of view, in talking about TL the "shift" in perspective or frame of reference to which so many refer relates to a shift in our consciousness (Dirkx, 2012), a profound connecting or reconnecting with what we have known to what has been unknown to us about ourselves and our being in the world. As you intimate, such concerns are not new. But I think we are increasingly able to articulate, through our theories and concepts, their complexity and how this complexity unfolds and evolves within our own individual and collective journeys. So another way of framing your question would be to ask, what does the theory (or theories) of TL help me see and understand about adult learning, social change, and development that I was not able to before coming to know about this idea?

LF: The name of the ESREA network on TL, "Interrogating transformative processes in learning," reflects our desire to not replicate what already exists in the United States but to engage in critical dialogue. Within the network, TL is examined within a deep interrogation. What are your thoughts on this?

JD: The idea of TL seems to point to a kind of learning that is substantively different from what we might otherwise regard as "good adult learning." This learning deeply involves the self of the person (group or community) with the process of learning. At the core of this process is a struggle for meaning and a realization of the selfhood of the learner, be it an individual or a collective. Because of its implication of the self in the process, this form of learning is often emotionally charged. Emotion-laden experiences are a clear signal that something deep with the psyche of the self has been evoked (Singer \& Kimbles, 2004). The tendency to blur the distinctions between learning that is transformative and learning that demonstrates "good learning" arises from our uncomfortableness in education, especially higher and adult education, to readily address and integrate these emotional issues into the learning and meaning-making process. For many years, educators have regarded the emotional dimension of learning as off-limits, demarcating the boundaries of their roles. While emotion and emotionality have received more attention recently by those concerned with educational issues, I think we have a ways to go in recognizing the integral and central role that emotion plays in meaning making, and how potentially disruptive this process can be to our ways of being in the world. There remain numerous ethical and practical issues to explore how we might more fully recognize and work with a person's emotional self in the learning process. 
Different regions and cultures reflect different ways of understanding and addressing this powerful dimension of adult learning. The articles that make up this special issue vary with regard to how they address the emotional dimensions of adult learning. The ambiguity that surrounds TL in our scholarly communities seems to mirror the ambiguity that characterizes our recognition and acceptance of the more affective or emotional dimensions of adult learning.

LF: What is learning? Where, why, how does it happen? We learn in different ways in different contexts. And new differences, new worlds, are becoming more active and visible in research: Eastern Asia, South America. Cultural differences matter. Are we aware of, and ready for, that?

I see "culture" as an ecology of entangled practices, ideas, values, and relationships, not as a closed system. Any attempt to bring some notion that was developed in a certain context into another one raises questions about "culture contact."

Among the aspects that TL does not address is the transformation of cultures, ecologies, and conversations, as a constitutive part of education. Learning is too often reduced to an individual and to intrapsychic events. This is what Bateson (1972) sees as an epistemological error - to forget the context of learning. Butas Bateson said, and Mezirow (1991) too-it arrives at a moment when serious epistemological errors stop working and we become reflexive about the way we see things.

JD: The question of epistemology is salient. Part of the difference you refer to seems to revolve around our fundamental assumptions about the nature of knowledge and how we come to know. These assumptions are also connected with or related to consciousness development at both the collective and individual levels. The history of science suggests this kind of evolution of our thinking about knowing and how we come to know. The enlightenment celebrated a certain way of thinking about knowledge and knowing. This paradigm provided us with a lens through which we could come to understand our worlds more thoroughly.

But we are now beginning to recognize the limitations and, indeed, some of the undesirable consequences of the scientific paradigm. We are beginning to see the disconnect that such a paradigm creates when imposed within cultures that value different ways of knowing and being in the world. For example, I was recently in Malawi for some fieldwork related to an international development project in which I am working. While I don't know a great deal about Malawian culture, rhythm and dance is a significant dimension of the country's culture. Yet, as we collected our data, there was little evidence that this aspect of the people's culture was manifest in any explicit way within postsecondary education.

Science reflects a certain way of viewing the world, of being in the world. Emotion, affect, and imaginative engagement, while certainly objects of scientific investigation, are not regarded as ways through which we come to know and understand ourselves and our being in the world. The so-called tension between "quantitative" and "qualitative" research reflects the deep ambiguity and difference that characterizes the scholarly community when it comes to what is accepted as legitimate paths to knowledge. Central to this debate is the notion of subjectivity and its 
place in our ways of knowing. All of this remind me of Thomas Kuhn's (1970) argument about how we progress in our understanding of the world and how it differed from a more traditional view of the growth of knowledge offered by someone like Karl Popper (1963).

Your assertion that learning is often interpreted as an individual and intrapsychic affair also highlights another important area of difference and reflects broader epistemological and ontological issues. This criticism has been directed towards me and others who have worked with a more psychological perspective. Yet, this charge tends to also blur important distinctions among scholars who work within this perspective. For example, my own work is heavily influenced by psychodynamic thought in general and Jungian and post-Jungian scholarship in particular. From these perspectives, learning and meaning making is intimately bound up within relationships and culture. An important connection exists between how I come to see and understand myself and the broader social and cultural contexts of which I am a part. In turn, an understanding of these broader social and cultural contexts require a deeper understanding of how individuals are perceiving and interpreting their being in the world. Neither lens provides a full understanding without the other.

I see TL through a similar set of lenses. Whatever this phenomenon is, it clearly is bound up within relationships. This view is not that dissimilar to systems theory (Meadows, 2008) and recent work on the nature of organizational change (Scharmer, 2009). In these frameworks, the individual, the interpersonal, and the social systems are all intertwined and all are needed to fully understand the nature of change taking place or how we might facilitate such change.

How do you create dialog across such differences? Is dialog even possible or do we simply end up talking past one another? As with the arguments that have raged across the sociology of knowledge, I think these questions might be put to those of us working within the area of TL.

\section{What Kind of Conversation Do We Need to Reframe TL?}

LF: A question that we could ask each other is, what do you see, feel, or think when I say "transformative learning"? What is "transformation" in your ecology of ideas? What is "the form that transforms," as Linden West and Knud Illeris both ask in their respective articles in relation to Kegan's (2000) question. Form is a metaphor. My own metaphor, the form that I see in the learning process is a spiral (Formenti, 2011), but many other images can be of help in developing new frames for adult education. "Soul work" (this is a metaphor of yours, right John?) is a way to open possibilities.

JD: Yes, the idea of TL evokes within me a certain kind of learning, a learning that is deeper, engaging of the self of the person, and potentially challenging his or her way of being in the world. Through TL we are fundamentally different somehow in some small way. It is a kind of knowing from which it is difficult to retreat without living in what Sartre and de Beauvoir referred to as "bad faith." 
It is also a kind of deep knowing that is bound up with the everydayness of our lives. While many of my colleagues regard TL as epochal, soul work suggests that such learning is intimately intertwined with our daily lives, the seemingly "routine" decisions and choices we often make through the course of the day that reveal, at some level, what we are struggling with in an ongoing way. For me, TL is the process through which individuation occurs; that is, the full development and realization of my selfhood. Again, this is not the same as individualization. Rather, it reflects the complex interpersonal and cultural contexts, as well as intrapsychic issues, to which I have referred earlier. Events may occur within the course of our everyday lives that feel to us like the proverbial whack alongside the head. But such events are often symbolic of broader psychic processes that underlie our lives and relationships. They point to the need for us to have a deeper conversation with ourselves, others, and our worlds. The idea of "journey" is often overused in such discussions, but that is how I think of this process. I feel as if I am on some kind of journey. In thinking about TL in this way, I regard the process as more important than the destination.

LF: Metaphors are subjective and collective, as Jung showed. For me, to reframe TL means to share metaphors and definitions and then develop some good ideas around them (as in Heron's cooperative inquiry process). We do not need to come to one overall big theory. Maybe the era of systematic and comprehensive theories is finished. Our perspectives are coherent with the inherent logic of the culture we were raised in, of our real and metaphorical families, and embedded in the language we talk, as well as in our practices. We cannot escape our experience and contexts that shape us, our theories and actions, bodies and dreams, emotional dispositions. Socialization both shapes and deceives us, transforming a set of possibilities into a set of necessities (Berger \& Luckmann, 1966) - and vice versa.

To avoid TL to become an hegemonic or ideological discourse, the antidote is dialogue. Dialogic knowledge is poly-vocal, it avoids meta-narratives and saturated stories and it praises difference and self-reflexivity, not truth or intrinsic validity (Norris, \& Sawyer, 2012).

There can be obstacles to that. As Lakoff and Johnson (1980) demonstrated, the relationship between ideas is often represented as a "war"; increasingly used metaphors come from the economical world. More conversational and democratic metaphors of knowledge treat ideas as offers, gifts, gestures, and moves, like invitations to dance. So, the word "transformation" can be used in multiple ways and can't be rejected or assumed by default. Transformational approaches in education are wider than TL, we should explore them.

JD: Your comments here remind me of a recent episode of the Diane Rehm show on National Public Radio (NPR). Her guest was Peter van Agtmael, and they were discussing his recent book, Disco Night Sept 11 (2014). In talking about what it was like to be a war photographer on the front lines, he referred to these experiences as "transformative." When he said this, I am quite sure he had neither Mezirow's nor my conception of TL in mind. What did he mean by this? 
It suggests, as you do in your comment here, that transformative experiences and transformation more generally are broader than TL. I think that is true. Like the concept of individuation, transformation can be conscious and unconscious. It can occur within the boundaries of our awareness or it can feel as if it came completely out of nowhere. It also can take place in most any contexts or locations. TL implies a conscious, voluntary participation in a process through which we come to greater awareness, understanding, or realization of our experiences and our being in the world. As a result, we are different somehow, and we generally know why and in what ways. This change process is often associated with a release of psychic energy, which becomes available to us in our continuing experiences.

LF: Another kind of conversation should build more awareness of the reasons behind the success of TL. Powerful ideas require the ability and commitment to engage in serious self-examination. It becomes interesting to track the historical roots and contexts of TL as an idea as well as the personal engagement of each proponent. There's a wealth of epistemological, cultural, and biographical material here that can enrich TL as a theory. Why did so many followers of Mezirow prefer the rational, cognitive, individual side of his theory, which is much more complex and open? Is it because they are American? Is it because of the promise of an exciting journey into awareness and clarity, as opposed to unconscious and dark things? Is this connected to an individualistic and ego-centered perspective? A sign of masculine White rationality? Am I creating a polarity here, between power and self-assertion, on one side, and inclusiveness, political correctness, and feminine virtues, on the other side?

In the larger community of TL, there seems to be an emerging possibility for a deeper appreciation of complexity, uncertainty, and ambiguity in human lives. As I see it, TL as an ecology of ideas invites us to be open to the possibilities of learning, accepting that we will never have the full picture. TL itself is not unquestionable, as it can grow and change. The map is not the territory. This is the moment to relinquish any authoritarian assumption.

JD: Laura, you raise yet another really interesting issue here. The conversation around the meaning of TL and the images that have animated this conversation over the years do reflect, I think, implicit sets of assumptions to which we, individually and collectively, have bought into. In earlier works, I argued that Mezirow's portrayal of TL as a critically reflective process reflected a kind of journey of the hero who overcomes all odds to be victorious over the perils of ignorance. To me it does seem to attribute considerable control and authority to one's ego and fails to recognize the darker, more powerful and unconscious forces that lurk just beneath the surfaces of our individual and collective lives.

From a Jungian perspective, we have introduced the idea of archetypes and how they can often shape and influence the meaning of collective experiences. From this perspective, we might think of these various versions of TL as reflecting commitments to logos or mythos (Labouvie-Vief, 1994). Mezirow's depiction, to me, clearly reflects a commitment to logos, while soul work reflects the characteristics and qualities, we might attribute to mythos. Neither, of course, is either right or 
wrong, but they do convey quite different worldviews, and notions of what it means to engage in TL. These commitments also reflect what I was discussing earlierhow we understand and make sense of the affective or the emotional within our lives. As we review and think about views of TL depicted in these four articles, as well as others, we might ask the extent to which their stories are stories of logos or mythos.

\section{In this issue}

LF: This collection of articles represents the power of TL to move different scholars in their own search for meaning, through the development of both a satisfying theory and relevant coherent practices. The first article was authored by two researchers of difference: Ed Taylor, an American and an experienced leading figure in the field, and a younger brilliant woman, Anna Laros from Europe. They engaged in a meta-reflection on recent developments in TL research, analyzing the scientific production and making a comparison with the analogous evolution of another leading theory, andragogy. This article raises many important points that I am longing to discuss in a larger group: Is transformation a specific goal for adult educators or a by-product of almost any kind of experience-based practice? Is learner-centered teaching a default attitude and value for all adult educators? Is it really and always possible, useful, authentic? Is it possible — or even ethical-to foster TL without negotiating it from the very beginning with learners? People are scared by "disorienting dilemmas"! Meaning develops in the ecology of ideas, through differences. I do not think that we can control it, but it seems necessary to find some commonalities, if we want to keep our conversations open. Taylor and Laros remind us that sometimes in the Babel of human intercourse we need to renegotiate the meaning of our actions and definitions, concepts and values, if we want to go on.

Knud Illeris identifies the search for identity, in relation to a changing environment as the target area of TL. He analyzes some different terms that are used to talk about it - person, individual, learner, personality, self, identity, soul, biographicity, competence - and explains why he chooses identity as "the right term." I like his epistemological attention for the frameworks of words and the effort to make explicit choices that could answer, at least partially, Taylor and Laros' worries. How do ideas come into being, transform, evolve? How do they take a "meaning"? Illeris makes a connection between the "conditions and frames of society" and the quest for identity, and draws a model of identity as an integrated multidimensional structure, that seems to be normative, at least in WEIRD, that is, Western, Educated, Industrialized, Rich, and Democratic societies (Henrich, Heine, \& Norenzayan, 2010). This article struggles with the necessity of finding "some sort of agreement or common notion" of TL, and it offers quite a concrete theoretical proposal and opens many questions for further conversations.

The third article stages quite a different mind-set, another worldview, a different paradigm, and another research method. Linden West is a leading character in 
auto-/biographical research. The focus of Linden's work invites us to de-center from the common sense of learning as a (purely) cognitive, disembodied, individual, conscious activity, as well as from a view of transformation as definitely positive, clear, like a solution, or a progression. His article develops connections between stories and TL, between form and transformation, and how we can build a satisfying theory. The desire to learn, as well as its clear expression in language, cannot be taken for granted: any theory that does not take into consideration these constraints risks to be too partial to celebrate the experience of learning. West warns us, it is necessary to connect stories of learning with the larger context, the psychological and the sociological, if we want to honor the complexity of life, the many contradictions and ambiguities, joys and sorrows, that come with learning, as it is clear in the case study he presents, where transformation is chronicled, and the learner seems aware of it, but somehow he shows how much this learning can be fragile, temporary, incomplete, and in process. As life is.

Alexis Kokkos (2012) closes this special issue with a very concrete question, "Could TL be appreciated in Europe?" Among European scholars, Kokkos has been one of the most committed and active in TL, which aptly positions him to start a discussion in Europe about TL, its theoretical framework, and the concrete positioning of European scholars in relation to it. He does it by referring mainly to the Greek community of adult educators and researchers, but his study gives some clues about the larger situation and is a stimulus to gain deeper knowledge of what is occurring in other countries. Specifically, how adult education is rapidly transforming and posing new questions, and how TL can be integrated with other theories and/or practices. This article addresses the need to connect more broadly and deeply TL to social action, conscientization, issues of power and critical thinking and relates this to the European tradition. This resonates with both West's and Illeris' positions, although in a different way.

This article also highlights as a crucial feature of TL-and maybe one of the reasons for its success-Mezirow's attitude toward his own ideas. His relationship to knowledge appears dialogic, conversational, and transformative itself. In fact, he proposes TL as a "theory in progress" and a "practical theory," integrated and open to change; very often his reactions to critiques were inclusive, aimed to gain a more comprehensive view of learning (that he recognizes as a complex object). $\mathrm{He}$ acted as a "midwife-teacher" (Belenky and Stanton, in Kokkos article), encouraging participation and composition of dualisms. While reading the article, I asked myself how many European scholars are ready to take such a role to be the ones who take care of a community, of the development of an ecology of ideas, and let their theory be freely reinterpreted by newcomers.

JD: The initial impetus given by Jack Mezirow has been celebrated by the work of scholars who have committed themselves to update and enrich the tradition of TL. Now, we are beginning a new challenging experience with this ESREA network. A new ecology of ideas that not only need to be brought together but used to enrich our work, our thought, and action. We need a set of shared (but not closed) concepts and a language to process diversity. This special issue outlines a few of 
the questions that can be asked about TL, there is still much to be explored, and exciting times lie ahead.

\author{
Laura Formenti \\ University of Milano Bicocca (Italy) \\ John Dirkx \\ Michigan State University
}

\title{
References
}

Bateson, G. (1972). Steps to an ecology of mind. New York, NY: Ballantine.

Bateson, G. (1979). Mind and nature. A necessary unity. New York, NY: Bantam Books.

Berger, P. L., \& Luckmann, T. (1966). The social construction of reality. A treatise in the sociology of knowledge. London, England: Penguin Books.

Boyd, R. D., \& Associates. (1991). Personal transformation in small groups: A Jungian approach. London, England: Routledge.

Dirkx, J. M. (2012a). Nurturing soul work: A Jungian approach to transformative learning. In E. W. Taylor, P. Cranton, \& Associates (Eds.), The handbook of transformative learning: Theory, research and practice (pp. 116-130). San Francisco, CA: Jossey-Bass.

Dirkx, J. M. (2012b). Self-formation and transformative learning: A response to "Calling transformative learning into question: Some mutinous thoughts." Adult Education Quarterly, 62, 399-405.

Formenti, L. (2011, May). Metaphors, stories and the making of a satisfying theory: Transformational learning for professionals in education. In M. Alhadeff-Jones \& A. Kokkos (Eds.), Transformative learning in time of crisis: Individual and collective challenges (pp. 102-108). Proceedings of IX International Conference on Transformative Learning, Athens, Greece.

Formenti, L., West, L., \& Horsdal, M. (2014). Introduction. Only connect: The parts and the whole. The role of biographical and narrative research? In L. Formenti, L. West \& M. Horsdal (Eds.), Embodied narratives. Connecting stories, bodies, cultures and ecologies (pp. 21-46). Odense, Denmark: University Press of Southern Denmark.

Henrich, J., Heine, S. J., \& Norenzayan, A. (2010). The weirdest people in the world? Behavioral and Brain Sciences, 33, 61-83. doi:10.1017/S0140525X0999152X

Kegan, R. (2000). What "form" transforms? In J. Mezirow and Associates (Eds.), Learning as transformation (pp. 35-70). San Francisco, CA: Jossey Bass.

Kokkos, A. (2012). Transformative learning in Europe: An overview of the theoretical perspectives. In E. W. Taylor \& P. Cranton (Eds.), Handbook of transformative learning: Theory, research and practice. San Francisco, CA: Jossey-Bass.

Kuhn, T. S. (1970). The structure of scientific revolutions. Chicago, IL: University of Chicago Press.

Labouvie-Vief, G. (1994). Psyche and eros: Mind and gender in the life course. Cambridge, England: Cambridge University Press. 
Lakoff, G., \& Johnson, M. (1980). Metaphors we live by. Chicago, IL: University of Chicago Press.

Meadows, D. (2008). Thinking in systems: A primer. White River Junction, VT: Chelsa Green.

Mezirow, J. (1991). Transformative dimensions of adult learning. San Francisco, CA: Jossey-Bass.

Newman, M. (2012). Calling transformative learning into question: Some mutinous thoughts. Adult Education Quarterly, 62, 399-411.

Norris, J., \& Sawyer, R. D. (2012). Toward a dialogic methodology. In J. Norris, R. D. Sawyer \& D. Lund (Eds.), Duoethnography. Dialogic methods for social, health, and educational research. Walnut Creek, CA: Left Coast Press.

Popper, K. R. (1963). Conjectures and refutations: The growth of scientific knowledge. London, England: Routledge \& Kegan Paul.

Scharmer, C. O. (2009). Theory U: Leading from the future as it emerges. San Francisco, CA: Berrett-Kohler.

Singer, T., \& Kimbles, S. L. (Eds.). (2004). The cultural complex: Contemporary perspectives on psyche and society. New York, NY: Routledge.

Varela, F. (1976). Not one. Not two. CoEvolution Quarterly, 11, 67-62. 